\title{
Articles
}

\section{A Preliminary Range-Wide Distribution Model for the Sacramento Valley Red Fox}

\author{
Benjamin N. Sacks,* Mark J. Statham, Heiko U. Wittmer \\ B.N. Sacks, M.J. Statham \\ Mammalian Ecology and Conservation Unit, Veterinary Genetics Laboratory, Department of Population Health and \\ Reproduction, School of Veterinary Medicine, University of California, Davis, One Shields Avenue/Old Davis Road, Davis, \\ California 95616
}

\section{H.U. Wittmer}

School of Biological Sciences, Victoria University of Wellington, P.O. Box 600, Wellington 6140, New Zealand

\begin{abstract}
The Sacramento Valley red fox Vulpes vulpes patwin of California is a newly named subspecies recently found to be distinct both from other native red foxes and nearby introduced populations. The Sacramento Valley red fox experienced a historical demographic bottleneck resulting in a critically small genetic effective population size, causing concern over its current status and management requirements, yet little is known about its contemporary abundance, demographic trajectory, or habitat use. The hot, arid Sacramento Valley contrasts starkly in climate and physiography with the boreal habitats of other indigenous red foxes in western North America, indicating the need to obtain information specifically on the habitat requirements of this subspecies. A 3-y effort to locate reproductive den sites throughout the Sacramento Valley resulted in 42 independent dens, which we used to obtain preliminary information on habitat use and to develop a distribution model for this subspecies, and 28 Sacramento Valley red foxes killed by vehicles, which we used as independent data to test the models. Foxes were present significantly more than expected in grasslands and less than expected in wetlands and flooded agriculture and also tended to occur in proximity to human development, potentially as refuges from coyotes Canis latrans. We used Maxent to build predictive models. The best model, which incorporated vegetation/land-use classes and proximity to human development, identified $24 \%$ of the study area as predicted-presence habitat, which contained $76 \%$ of the den sites used to construct the model and $89 \%$ of independent locations used to test the model. Our model greatly narrowed the area over which foxes are predicted to occur and will facilitate future surveys to assess occupancy and ultimately abundance and population trends.
\end{abstract}

Keywords: California; habitat; Maxent; Sacramento Valley red fox; species distribution model; Vulpes vulpes patwin

Received: July 20, 2015; Accepted: December 30, 2016; Published Online Early: December 2016; Published: June 2017

Citation: Sacks BN, Statham MJ, Wittmer HU. 2017. A preliminary range-wide distribution model for the Sacramento Valley red fox. Journal of Fish and Wildlife Management 8(1):28-38; e1944-687X. doi:10.3996/072016-JFWM-057

Copyright: All material appearing in the Journal of Fish and Wildlife Management is in the public domain and may be reproduced or copied without permission unless specifically noted with the copyright symbol (c). Citation of the source, as given above, is requested.

The findings and conclusions in this article are those of the author(s) and do not necessarily represent the views of the U.S. Fish and Wildlife Service.

* Corresponding author: bnsacks@ucdavis.edu

\section{Introduction}

The Sacramento Valley red fox Vulpes vulpes patwin is an ecologically distinct subspecies endemic to California (Figure 1; Perrine et al. 2007; Sacks et al. 2010a). This fox is one of four subspecies in a phylogenetically divergent lineage native to the western United States. In contrast to other native western red foxes, which occur in highelevation subalpine environments dominated most of the year by snow cover, this subspecies is restricted to elevations below $150 \mathrm{~m}$ on the floor of California's Sacramento Valley (bounded on three sides by moun- 


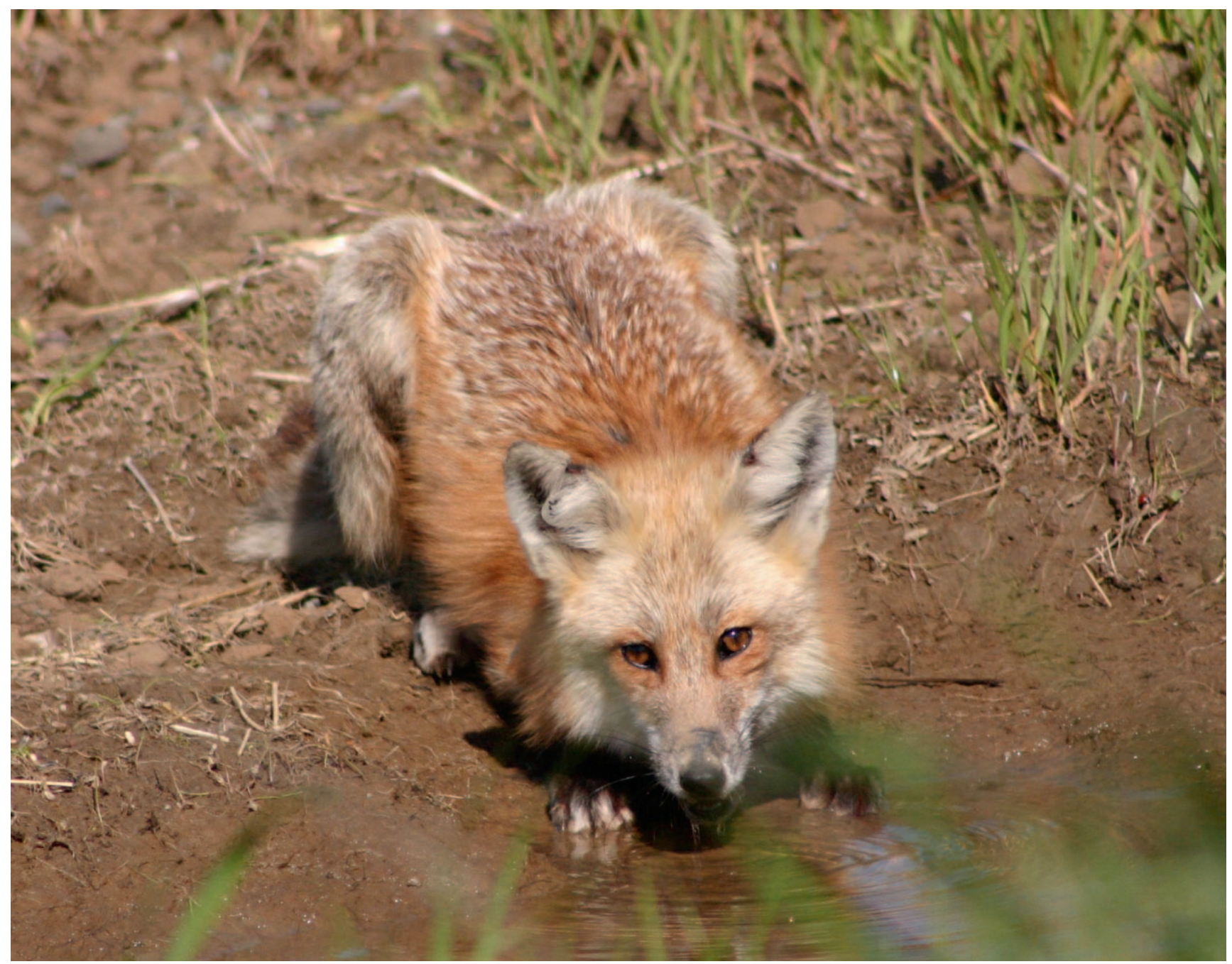

Figure 1. A Sacramento Valley red fox Vulpes vulpes patwin lapping water from a puddle near Capay, California, March 31,2010 (photo by B.N. Sacks).

tains), where summer temperatures frequently exceed $40^{\circ} \mathrm{C}$ and winter temperatures rarely dip below freezing. The hot, arid environment in the Sacramento Valley is so anomalous that for nearly a century these native red foxes were presumed to stem from introduced foxes from the eastern United States and were thus misclassified as a nonnative species (Grinnell et al. 1937; Roest 1977; Jurek 1992; Lewis et al. 1999).

In addition to being a California native, new genetic studies of historical and modern continent-wide samples indicate that the Sacramento Valley red fox underwent a recent genetic bottleneck, resulting in a current genetic effective population size of $\sim 50$ (Sacks et al. 2010a). Moreover, the genetic integrity of Sacramento Valley red foxes has been maintained largely intact despite introductions in the 1900s and subsequent spread of feral red foxes (originating from fur farms), which currently occupy most other low-elevation regions of California (Sacks et al. 2016). Thus, despite the superficial similarities in the appearance of native and nonnative lowland red foxes and low levels of hybridization, native red foxes in the Sacramento Valley have maintained their genetic distinctiveness, possibly as a consequence of social reproductive barriers (Sacks et al. 2011). At present, however, little is known about the status of the subspecies, including its census population size, threats to its persistence, or basic habitat use (Sacks et al. 2010a). Consequently, the Sacramento Valley red fox is currently under consideration for listing as a California state "Mammal Species of Special Concern," which indicates the need for more information to assess potential threatened or endangered status (S. Osborn, California Department of Fish and Wildlife, pers. comm.).

As an essential step in this process, our goal in the present study was to develop a model delineating the predicted spatial distribution of the Sacramento Valley red fox throughout its range. In 2007, we initiated a study to determine the range extent and genetic integrity of Sacramento Valley red foxes relative to an adjacent red fox population comprised of individuals of known nonnative ancestry (Moore 2009; Sacks et al. 2010a, 2010b, 2011; Converse 2012). As part of our efforts, we documented the presence of reproductive den sites and red foxes killed by vehicles (hereafter, 
"road kills") of the native subspecies, which can be used to describe and map habitats supporting foxes.

The most powerful approach to modeling species distributions involves sampling random locations to determine both presence and absence (Guisan and Zimmerman 2000; MacKenzie et al. 2006). However, when little is known about the correlates of a species' distribution over large regions, presence-only data can provide a more efficient and practical means of developing preliminary distribution models, which, in turn, can be used to guide more efficient and robust occupancy surveys in the future (Guisan et al. 2006; Peterman et al. 2013). When sample sizes allow, likelihood-based resource selection functions (Johnson et al. 2006) combined with information-theoretic methods of model selection and averaging (Burnham and Anderson 2002) offer powerful presence-only approaches to statistically test selection of land-cover types and estimate probabilities of occurrence (Royle et al. 2012). However, when the goal is simply to produce qualitative estimates of a species distribution, algorithmic approaches such as maximum entropy modeling in Maxent tend to produce very similar results (Warton and Aarts 2013), and may produce more realistic models with smaller sample sizes (Phillips et al. 2004, 2006; Pearson et al. 2007; Wisc et al. 2008). Our intent was to use the modestsized set of available data to identify areas of predicted red fox presence to provide the basis for more extensive presence-absence surveys in the future (e.g., Guisan et al. 2006). We therefore used Maxent modeling for this purpose.

\section{Study site}

Our study area comprised the entire putative native range of the Sacramento Valley red fox $\left(\sim 12,000 \mathrm{~km}^{2}\right.$, elevations $<150 \mathrm{~m}: 39^{\circ} 21^{\prime} 36^{\prime \prime} \mathrm{N}$ to $40^{\circ} 23^{\prime} 60^{\prime \prime} \mathrm{N}$; $122^{\circ} 15^{\prime} \mathrm{W}$ to $121^{\circ} 25^{\prime} 48^{\prime \prime} \mathrm{W}$; Sacks et al. 2010b). Historically, the southern Sacramento Valley was a large flood plain containing two major rivers (Feather and Sacramento and their tributaries), both of which also supported dense riparian forests up to $8 \mathrm{~km}$ wide (Thompson 1961; Gibson 1975). To the west of the Sacramento River riparian corridor were marshes lined on either side by slightly raised grasslands. Today, the landscape of the Valley is much changed through anthropogenic alterations, such as levees containing the rivers and tributaries as well as the conversion of $>$ $90 \%$ of the historical riparian and $\sim 65 \%$ of historical grasslands to agricultural lands (Nelson et al. 2003). In the lowest elevations of the valley (roughly associated with the floodplain), flooded rice agriculture has replaced naturally flooded lands. In more upland portions of the valley, much of the grasslands have been replaced by dry cropland, vineyards, and orchards. Remnant grasslands remain where livestock are grazed, although the composition of grass and forb species has changed dramatically. Once dominated by native perennial and annual grasses, grasslands are now dominated by exotic annual species (Barbour et al. 2007). Overall, the current composition of land-cover type in the
Sacramento Valley is approximately 36\% dryland agriculture, 26\% flooded agriculture, 29\% grasslands, 5\% wetlands, and $4 \%$ woodlands.

\section{Methods}

\section{Presence sampling}

During 2007-2009, we documented the presence of reproductive den sites and road kills of Sacramento Valley red foxes, which provided the presence data for this study. Specifically, we used reproductive den sites of native red foxes $(n=42)$ as presence locations (Table S1, Supplemental Material) to build models and used 28 opportunistically collected road-killed red foxes (Table S2, Supplemental Material) to test model generality (Sacks et al. 2010b). Use of reproductive den sites had the advantage of providing precise locations known a priori to be associated with reproductive habitat. The road-killed red fox locations were collected throughout the year and therefore expected to represent habitat more broadly, including habitat used during fall and winter dispersal, and, because they were tied to roadways, to be influenced by different detection biases.

Ideally, our presence data would have reflected a random sample from the population. However, the extent of the study area, its domination by private land, and the general sparseness of red fox occurrence necessitated a haphazard approach to locating dens. To detect native foxes, we established a web-based reporting system (http://foxsurvey.ucdavis.edu) and utilized local news outlets and environmental, agricultural, and animal control organizations to advertise a request for red fox sightings throughout the Sacramento Valley and surrounding areas (Brasch 2013). Advertisements were concentrated in early spring to maximize the probability that red foxes were observed near den sites. We performed den searches near reported sightings. When active burrows or aboveground sightings of neonatal pups were located, we recorded locations with a global positioning unit. As described in detail previously in a genetic study that utilized the same specimens as the present study (Sacks et al. 2011), fresh scats were collected from near den entrances for genetic analysis (mitochondrial cytochrome $b$ and D loop sequencing, microsatellites) to confirm species and population of origin. Likewise, road kills also were genetically assigned previously (Sacks et al. 2011) to assess population of origin. Because some den sites and road-killed foxes on the periphery of the native range were determined to reflect hybrids between native and nonnative red foxes, in the present study, we used only dens and road-killed foxes in our analysis for which genetic assignment had previously indicated pure native ancestry (Sacks et al. 2011).

\section{Land-cover classification}

Vegetation types were defined on the basis of the California Central Valley wetlands and riparian geo- 
graphic information system (GIS) data layer, a vegetation coverage based on 1997 Landsat imagery (30-m resolution), projected in Teale Albers (State System: California Albers) NAD83 in Vector format (Tuffly and Kilgore 1998). This layer included 14 vegetation classes, pooled for the present study into the following six classes: 1) wetland (seasonally flooded estuarine emergents, permanently flooded estuarine emergents, tidal estuarine emergents, seasonally flooded palustrine emergents, permanently flooded palustrine emergents, tidal flats), 2) flooded agriculture (flooded agriculture, seasonally flooded agriculture), 3) dryland agriculture (nonflooded agriculture, orchards/vineyards), 4) woodland (riparian woody, nonriparian woody), 5) grasslands, 6) "development" (other). Generally, development indicated small buildings, such as barns, stables, sheds, and houses. At localized spatial scales, vegetation classes during the study period undoubtedly differed in many cases from those reflected in the vegetation layer composed 10 y before the start of our study; such discrepancies may have had the effect of introducing noise into our analyses, but are unlikely to have introduced systematic bias into species distribution modeling results.

\section{Data coding in GIS}

On the basis of historical accounts of the Sacramento Valley red fox, we anticipated that grasslands reflected prime foraging habitat (Grinnell et al. 1937). On the basis of studies of red foxes in landscapes similar to modern-day Sacramento Valley, we anticipated that proximity to human development conferred protection against coyotes (Dekker 1983; Sargeant et al. 1987; Sargeant and Allen 1989; Gosselink et al. 2003). We used ArcGIS (v10.0; Environmental Systems Research Institute, Redlands, CA) to project locations of red fox den sites, road kills, and 34,500 randomly generated points (i.e., a density of $\sim$ three points per square kilometer) and coded them with respect to the three explanatory variables: 1) vegetation class, 2) distance to grasslands (DistGrass), and 3) distance to development (DistDev). The layer containing the six habitat classes described above was used for the categorical habitat variable. We used the spatial analyst extension to create the two distance-based layers as follows: we 1) selected the habitat type from habitat layer and transferred it to its own layer; 2) used the Euclidean distance function to create a raster with each $100-\mathrm{m}$ grid cell coded in terms of its average distance to the habitat type; 3 ) reclassified grid cells into six distance-class partitions (0-1 km, 1-2 $\mathrm{km}, \ldots,>5 \mathrm{~km}$ ); 4) converted the reclassified raster to a vector-based shapefile, and 5) projected the shapefile into Teale Albers (NAD83). Creation of shapefiles from models was similar except that we used ordinary kriging to interpolate model projections of the 34,500 random points into a raster (output cell size $=465 \mathrm{~m}$ ), which was then reclassified and projected into Teale Albers.

\section{Land-cover use vs. availability}

As a purely descriptive prelude to modeling, we examined land-cover association via a comparison of observed with expected numbers of den locations in the six vegetation types using a chi-square goodness-of-fit test under the null hypothesis: occurrence proportional to availability (Zar 1999). Expected numbers were calculated for each type by multiplying its proportional contribution to the study area by the total number of locations in the study area. Following an overall significant deviation from expectation, each individual vegetation class was tested by dichotomizing habitat into that class vs. all other classes combined and tested for significance with a Fisher exact test. The continuous variables DistGrass and DistDev were similarly tested using a Kolmogorov-Smirnov goodness-of-fit test (Zar 1999).

\section{Maxent models}

We used a maximum entropy-based modeling approach implemented in Maxent, considered to be the most robust algorithmic technique when presence-only data are used (Elith et al. 2006; Phillips et al. 2006; Phillips and Dudík 2008). Note, we refer to vegetation class as a single categorical variable with six "levels" (i.e., the vegetation types indicated above) rather than as six variables. DistGrass and DistDev were treated as continuous variables. To account for the possibility of a bias owing to higher detection probabilities near developed areas, we built one model that excluded distance to development ("two-variable" model) for comparison with the model including all three variables ("full" model). Final models corresponded to averages across 10 replicate runs (10 random partitions). We followed recommendations of Phillips and Dudík (2008) for model specification (e.g., we used "hinge" features, and $\beta=$ 0.5 ). We used model output in logistic format but did not treat this in a literal sense as a quantitative estimate of probability of occurrence (Yackulic et al. 2012), or even as directly proportional to probability of occurrence, but rather as an ordinal, qualitative index, which we ultimately dichotomized (see below).

\section{Model evaluation}

We used both "internal" and "external" approaches to validating models. Internal approaches involved performance measures and random partitions for cross-validation procedures targeted to the den site presence points used to train and build models, whereas external approaches involved using spatially and functionally independent data sets for building (training) and evaluating (testing) models. For internal measures, we assessed discriminatory ability of models on the basis of the area under the (receiver-operating characteristic, ROC) curve (AUC) with statistical significance based on cross-validation using 10 random partitions of the data; for each of the 10 runs, we used $90 \%$ of the presence data to train models and used the excluded $10 \%$ of the data for 
testing. The value of AUC indicates the potential accuracy of a model in predicting a dichotomous outcome, in this case whether foxes are present or not at a given location. A model that predicts outcome no more accurately than random has $A U C=0.50$, whereas a model that always predicts correctly has AUC $=1.00$. Importantly, however, even a model that perfectly captures the habitat characteristics determining a species' distribution can still exhibit a relatively low AUC if, for example, not all suitable habitat is occupied or if no particular cutoff in predicted probability of occurrence corresponds well to a dichotomization of the habitat. Thus, we used AUC primarily as a relative means of comparing models rather than as an absolute measure of a model's utility. Similarly, the relative contribution of each variable to the model was assessed by "permutation importance," which provides an index of each variable's influence on the model through a comparison of the AUC resulting when the variable is coded correctly with that when its values are permuted among data (presence and background points), causing the variable to be nonsensical (Phillips et al. 2006; Phillips and Dudík 2008). The effects are then standardized across variables so that their relative contributions sum to 1 .

We used two external validation approaches. First, we used the road-kill data, which were collected year-round (including fall/winter dispersal), to test models built with den-site data. These two data sets potentially reflected different habitat variables, den sites corresponding closely to reproduction, and road kills potentially more reflective of dispersing individuals. Habitat models based on life requisites associated with established home ranges (e.g., reproduction) are not necessarily good predictors of how individuals move across the landscape during dispersal. Therefore, discrepancies would be equivocal with respect to whether they reflected biological differences or poor performance of the model. On the other hand, high agreement between model predictions and road-kill data would provide independent validation of the model and an indication of the model's generality.

The second evaluation approach was to divide the study area into northern and southern portions (divided at latitude $38^{\circ} 55^{\prime} 48^{\prime \prime} \mathrm{N}$ to equalize numbers of den sites), and use data from each portion to develop a model extrapolated to the other portion. For this task, we used the "mask" function implemented in Maxent and projected the model onto the opposite portion of the study area. The ability of the model trained in one portion of the study area to accurately predict presence in the other portion provided a conservative measure of model accuracy unaffected by spatial autocorrelation (e.g., Sacks et al. 2004). Extrapolative model performance also provided an indication of the generality of the model (Elith et al. 2010).

\section{Model dichotomization}

The application of models and our ability to compare their performance against independent data sets (i.e., road kills, den sites in other portion of study area) required us to dichotomize model predictions into areas of predicted presence vs. predicted absence. This task required identification of model-specific thresholds. Several criteria have been used previously to select such thresholds, including values that result in estimated $100 \%$ sensitivity (minimum value among presence sites) or $90 \%$ sensitivity (10 percentile value from presence sites). Use of the minimum value ( $100 \%$ sensitivity) is highly sensitive to sample size (Pearson et al. 2007). Similarly, use of $90 \%$ (or any other) sensitivity value is arbitrary and may not necessarily result in the most useful predictions. When reliable absence data are available, both sensitivity ( 1 minus the proportion of presence sites omitted) and specificity (1 minus the proportion of absence sites committed) can be used to select a threshold based on maximizing discriminatory value. Although specificity cannot be directly estimated from presence-only data sets (as in our study), the specificity of a model is inversely proportional to the proportion of the study area ("fractional area") where presence is predicted (Phillips et al. 2006). More intuitively, a model that minimizes the proportion of the study area where presence is predicted while maximizing inclusion of known-presence sites is potentially more informative than a model that achieves a similar sensitivity by predicting presence in most of the study area (Engler et al. 2004). Therefore, we chose threshold values for each model on the basis of maximizing the difference between fractional area and estimated sensitivity (proportion of presence sites included).

For the purposes of evaluating the extrapolated models against the model trained on all den-site data, we quantified correlations of their dichotomized predictions using a phi $(\varphi)$ coefficient, which is analogous to a Pearson correlation coefficient (ranging from -1 to 1 ), but for use on a $2 \times 2$ matrix (Zar 1999). For these comparisons, we used threshold values for the extrapolated models that resulted in the same fractional values as the model trained on all data. This procedure, also referred to as the "equalized predicted area test" (Phillips et al. 2006), ensured that any disagreement between models stemmed from qualitative differences rather than as an artifact of the particular threshold selection. We then composed GIS layers from the difference between model predictions.

\section{Results}

\section{Land-cover associations of den sites}

The red fox den sites occurred in vegetation classes disproportionately to the composition of the study area (Figure 2; Figure S1, Supplemental Material; $\chi^{2}{ }_{3} \mathrm{df}=9.1, P$ $=0.028$ ). In particular, den-site occurrences exhibited a higher-than-expected correspondence to grasslands (50\% use vs. $29 \%$ availability) and a lower-than-expected correspondence to flooded agriculture (5\% use vs. $26 \%$ availability), both of which differed significantly from random expectations ( $P=0.028,0.005$, respectively). 

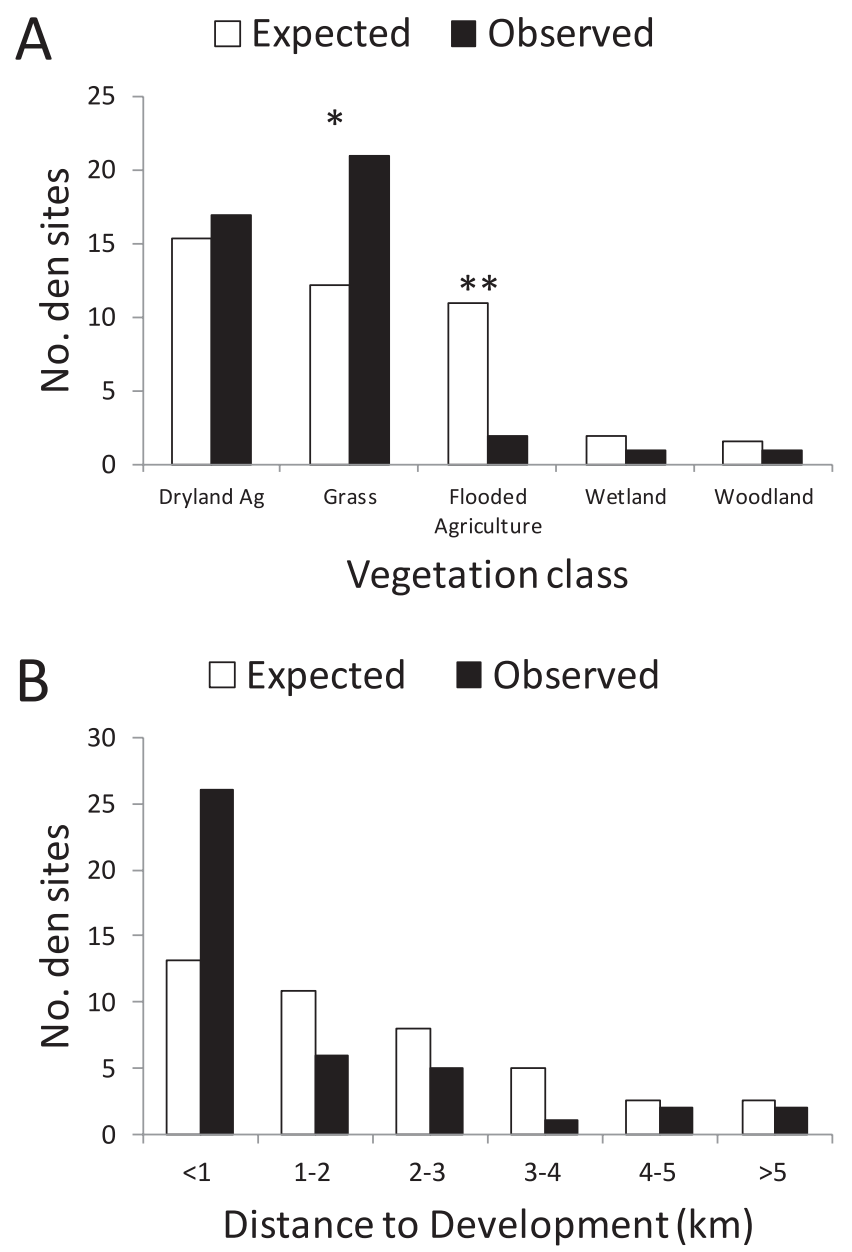

Figure 2. Observed vs. expected (if random) frequency distributions of Sacramento Valley red fox Vulpes vulpes patwin den sites with respect to (A) five habitat classes and (B) distances from the nearest mapped human structure. Expected numbers were proportional to corresponding classifications of 34,500 randomly generated points. ${ }^{*} P<0.05$, ${ }^{* *} P<0.01$. Data were collected during 2007-2009 in the Sacramento Valley, California.

Additionally, den sites tended to occur closer than expected to grasslands and development (Figure 2), but only the latter association was statistically significant $(P$ $<0.001)$.

\section{Maxent models}

The full Maxent model (including all three variables) performed better than the two-variable (i.e., excluding DistDev) model (Table 1). In particular, using a 0.38 threshold in the full model achieved an estimated sensitivity of $76 \%$ (i.e., included $76 \%$ of presence locations) and encompassed only $24 \%$ of the study area (52\% difference), whereas a threshold of 0.33 in the twovariable model yielded a slightly higher estimated sensitivity (89\%) but also encompassed a much higher proportion (59\%) of the study area (30\% difference). In general, the differences in the two models were minimal, and both models ranked habitats similarly (Figure 3; Figure S2, Supplemental Material). The contribution of DistDev in the full model was estimated to be two-thirds as important as vegetation class (Table 1).

A total of 23 of the 28 road kills $(83 \%)$ occurred in the $24 \%$ of the study area where the full model predicted red fox occurrence, whereas 27 of them (96\%) occurred in the $59 \%$ of the study area where the two-variable model predicted presences (Figure 4). In both cases, these proportions were higher than those associated with the den-site data set used to train the models in the first place (i.e., $76 \%, 89 \%$, respectively). Superimposing the full and two-variable models indicated habitat tracts predicted by the two-variable but not the full model, which can provide the basis for future occupancy surveys to test between these models (Figure 5).

\section{Extrapolations of models and tests with independent presence locations}

The use of southern and northern portions of the study area to train models (full model in all cases) for extrapolation to the opposite portion of the study area provided a spatially independent test of the modeling approach. The model based on den sites from the northern portion of the study area performed extremely well as evaluated against the presence sites (i.e., den + road kill) in the southern portion of the study area. In particular, $97 \%$ of presence sites in the southern portion of the study area were contained in the $29 \%$ of that region falling above the model probability threshold (68\% difference between sensitivity and fractional area). The model based on den sites from the southern portion of the study area performed less well as evaluated against the presence sites in the northern portion of the study area. In particular, $90 \%$ of presence sites in the southern portion of the study area were contained in the $50 \%$ of that region falling above the model probability threshold $(40 \%$ difference between sensitivity and fractional area). The correlations between the original full model (i.e., trained on all den sites) and the

Table 1. Summary of Maxent Sacramento Valley red fox Vulpes vulpes patwin distribution models, including the percent contribution of each variable to the model (permutation importance), area under the (receiver-operating characteristic, ROC) curve (AUC), and cross-validated AUC (CV-AUC). Standard deviations among 10 random partitions (90\% training, 10\% test) are shown in parentheses. Data for models were collected during 2007-2009 in the Sacramento Valley, California.

\begin{tabular}{lccccc}
\hline \multicolumn{5}{c}{ Permutation importance (\%) } \\
\hline Model & Habitat class & DistGrass & DistDev & AUC & CV-AUC \\
Full model & 57 & 3 & 40 & $0.76(0.01)$ & $0.71(0.12)$ \\
Two-variable model & 88 & 12 & - & $0.70(0.01)$ & $0.68(0.10)$ \\
\hline
\end{tabular}




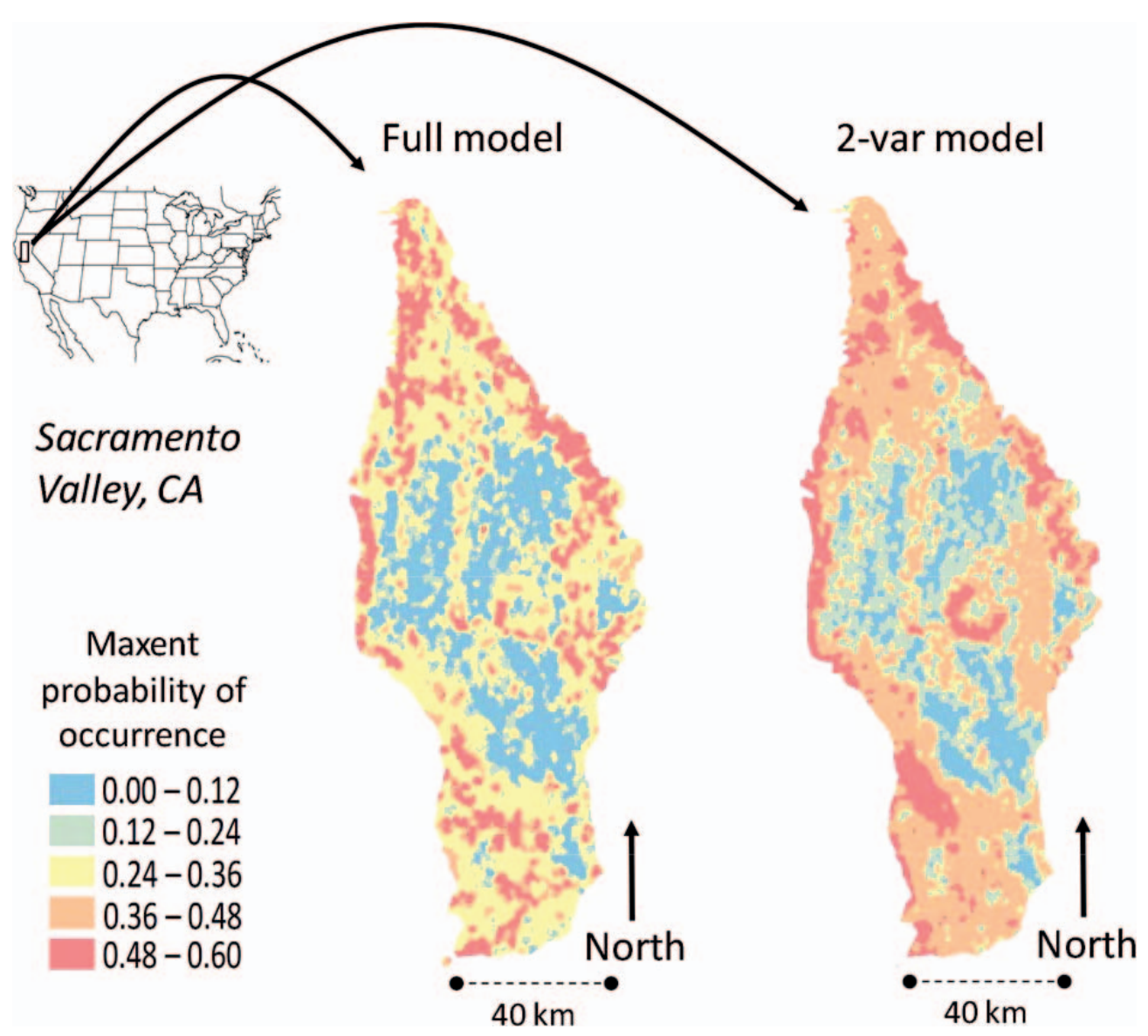

Figure 3. Maxent models of Sacramento Valley red fox Vulpes vulpes patwin distribution; the full model included vegetation type, DistGrass, and DistDev, and the two-variable (2-var) model included only vegetation type and DistGrass. Data were collected during 2007-2009 in the Sacramento Valley, California.

extrapolated models also were higher for the north-tosouth $(\varphi=0.96)$ than the south-to-north $(\varphi=0.72)$ model.

\section{Discussion}

The purpose of our study was to develop preliminary distribution models for the Sacramento Valley red fox for use in guiding future occupancy surveys. The areas under the ROC curves were not especially high ( $70 \%)$, suggesting that the ability of the models to predict occurrence in any particular location was limited. However, the best test of the accuracy of the models in an operational sense was our attempt to extrapolate models trained on one half of the range to predicting presence in the other half of the range, both of which performed reasonably well. The model built from the northern data performed better when extrapolated to the southern portion of the range than did the reverse operation. Although the sample sizes used to build each model were equivalent, the northern portion of the Valley was larger in terms of area and, more important, better represented by the range of the vegetation classes, especially flooded agriculture. Taken together, however, these tests bode well for the utility of the models built using the complete data set.

The predictive value of the model depends not only on the accuracy of the models with respect to capturing the selected components of habitat, but also on the extent to which typically selected habitats are occupied (and typically unselected habitats unoccupied), which can only be determined through independent future surveys guided by the model (e.g., Peterman et al. 2013). Such surveys would produce an estimate of occupancy within predicted-presence (and predicted-absence) habitat, which also would provide the basis to estimate the abundance of Sacramento Valley red foxes from locally obtained data on home range and family group size. Additionally, future surveys would also enable detection of any hidden biases associated with the present models (see below).

In terms of habitat selection, our findings (i.e., selection for grasslands) were broadly consistent with historical records indicating that red foxes denned in excavated California ground squirrel Otospermophilius beecheyi burrows on uncultivated ridges and avoided the lower-elevation areas more prone to seasonal flooding (Grinnell et al. 1937; Sacks et al. 2010b). Additionally, a demographic decline in Sacramento Valley red foxes during the past century and a half (Sacks et al. 2010a) 


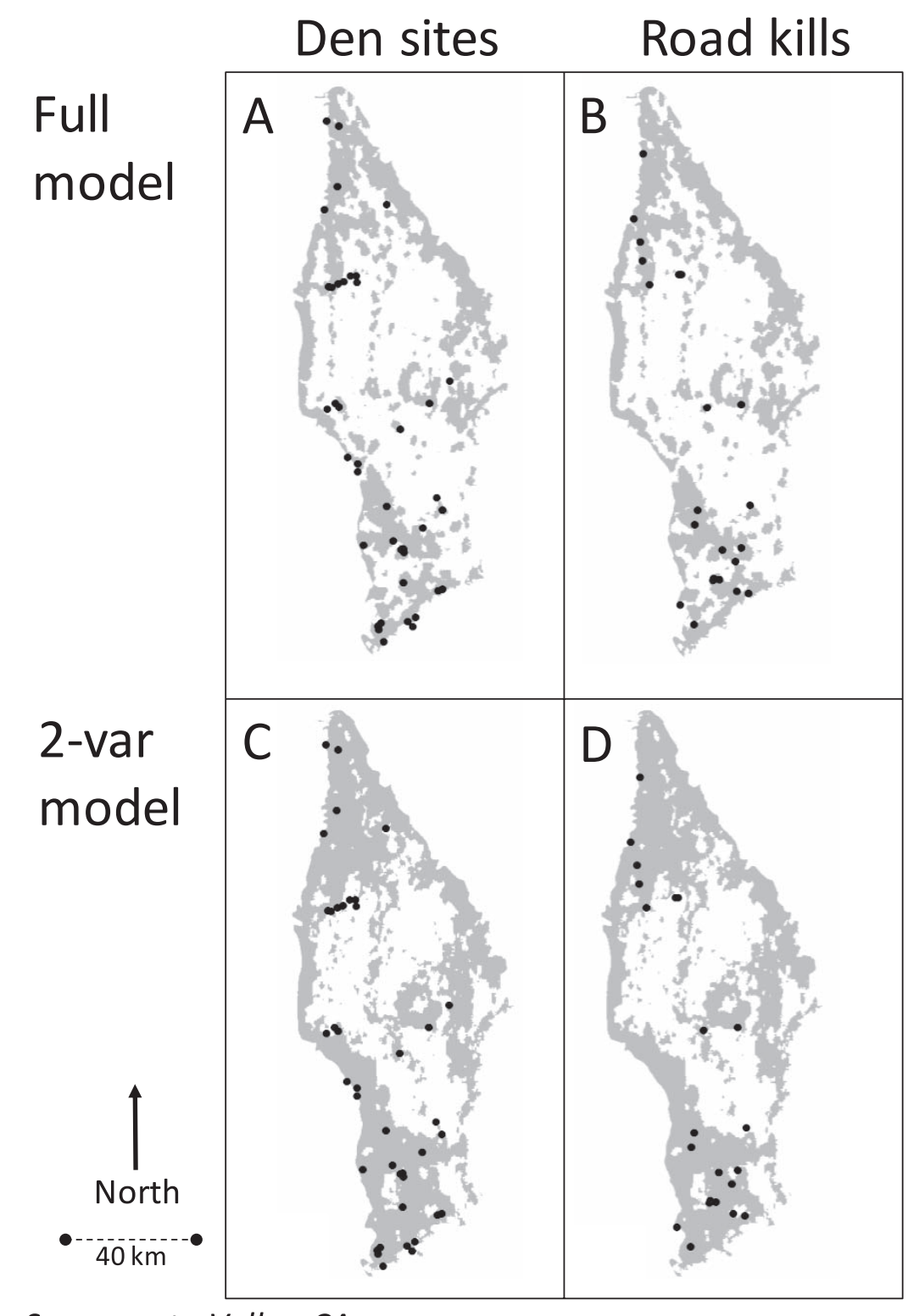

Sacramento Valley, CA

Figure 4. Dichotomized Maxent models of Sacramento Valley red fox Vulpes vulpes patwin distribution in reference to den sites (black dots) used to create models ( $A, C)$ and road-killed foxes (black dots) that were independently collected (B, D); models included vegetation type, DistGrass, and DistDev $(A, B)$ or vegetation type and DistGrass only $(C, D)$, and were dichotomized into predicted presence (gray) and absence (white) on the basis of threshold logistic probabilities that maximized the difference between estimates of sensitivity and proportion of study area defined as "suitable habitat" (fractional area). Data were collected during 2007-2009 in the Sacramento valley, California.

coincided with the loss of $65 \%$ of the historical grasslands from the Sacramento Valley (Nelson et al. 2003). The tendency for Sacramento Valley red foxes to establish den sites closer to human development was noteworthy. On the one hand, our use of voluntary reports to guide us to den sites could have introduced a bias, whereby human presence and perhaps land use (if correlated with human attitudes and willingness to report) influenced the probability that we would discover a given den (Brasch 2013). On the other hand, it is unlikely that any such bias alone was sufficient to explain the apparent selection. In contrast to sighting reports of free-ranging foxes, road kills were subject to many more eyewitnesses and probability of their detection was unlikely to be dependent on the surrounding habitat (i.e., proximity to human structures). Fine-scale observations further support the selection of human development by Sacramento Valley red foxes. For example, we documented several dens under sheds or woodpiles, in culverts, road cuts, and between buildings (Sacks et al. 2010b). Radiocollared individuals were also frequently located in edge habitat sandwiched between buildings and agricultural fields and tended to avoid areas farther from human structures unless heavy cover 


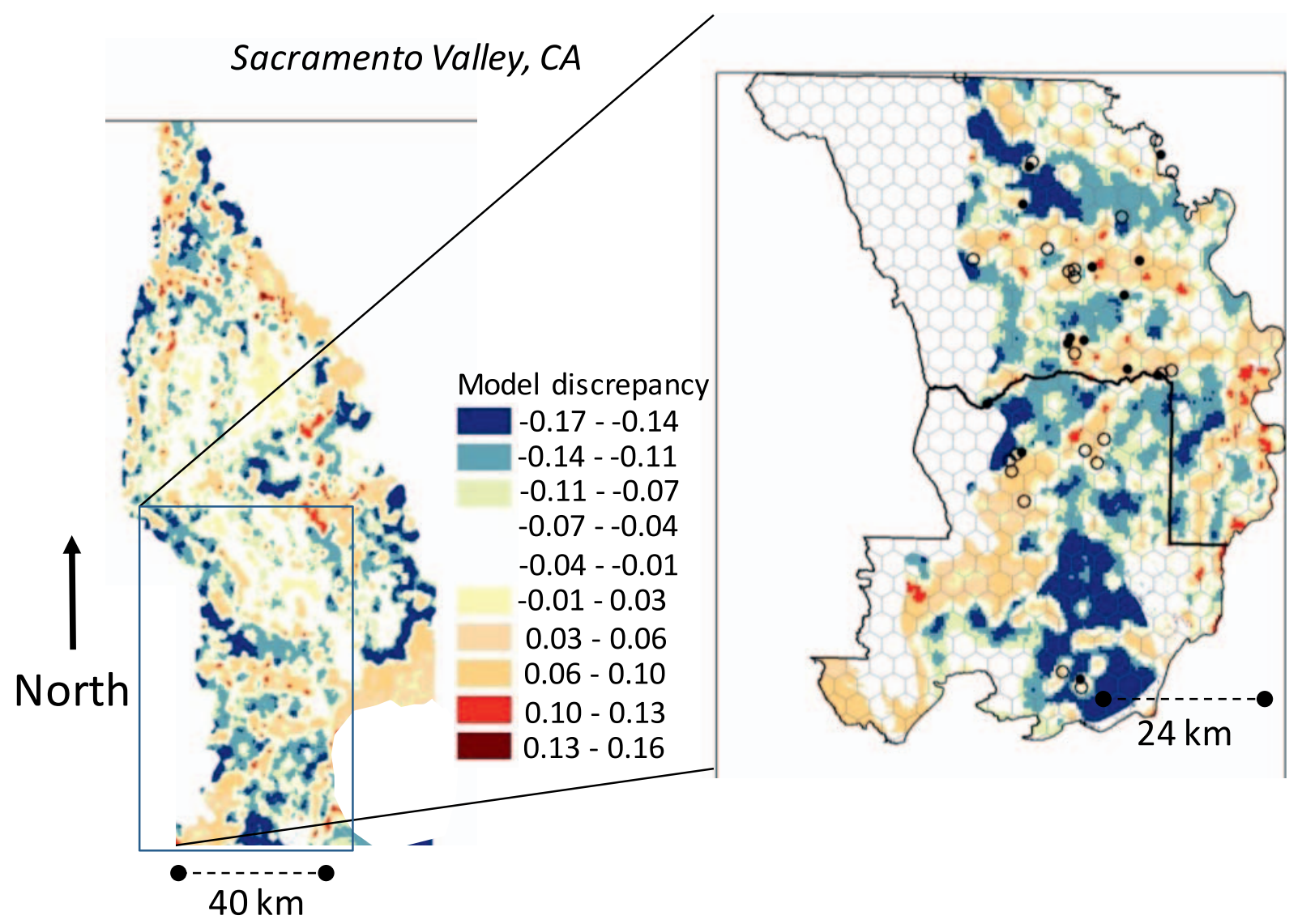

Figure 5. Difference in probability of Sacramento Valley red fox Vulpes vulpes patwin presence predicted by the Maxent model using all three variables vs. the two-variable model (i.e., excluding development). The values represent differences in logistic probabilities (full - two-variable). Dark blue areas correspond to grasslands not immediately adjacent to development where the two-variable model, but not the full model, predicts high probability of red fox occurrence. Inset shows locations of den sites (open circles) and road-killed red foxes (filled circles) along with a hexagonal $\left(10.4 \mathrm{~km}^{2}\right)$ grid that can provide the basis for future validation surveys. Data were collected during 2007-2009 in the Sacramento Valley, California.

was nearby (B.N. Sacks, unpublished data). We hypothesize that importance of human structures in the contemporary Sacramento Valley landscape relates to predation refuges from coyotes, a larger, sympatric, and competitively dominant canid. Coyotes compete with red foxes both through exploitation and interference and are known to be important determinants of red fox distribution and abundance in other parts of their range (Dekker 1983; Sargeant et al. 1987; Sargeant and Allen 1989; Gosselink et al. 2003; Van Etten et al. 2007; Levi and Wilmers 2012). Nevertheless, we developed a model excluding proximity to human development specifically so that future surveys can be stratified in terms of areas where both models predict occurrence vs. where the two-variable but not the full model predicts occurrence, enabling independent, unbiased assessment of the relationship of human development to fox occurrence.

Our study was a broad-brush attempt to characterize and delineate potential habitat for the Sacramento Valley red fox. Our findings considerably narrowed the area within the Sacramento Valley over which native foxes are predicted to occur, facilitating subsequent steps in assessing conservation status, determining threats, and monitoring. Chief among these steps will be to system- atically or randomly survey predicted-presence habitat to assess occupancy and to use these results in combination with estimates of home range and group size to estimate the population abundance of this endemic subspecies.

\section{Supplemental Material}

Please note: The Journal of Fish and Wildlife Management is not responsible for the content or functionality of any supplemental material. Queries should be directed to the corresponding author for the article.

Table S1. Locations and land-cover-type coding of 42 Sacramento Valley red fox Vulpes vulpes patwin den sites used in Maxent modeling, Sacramento Valley, California, 2007-2009. Location data are provided in Excel format in decimal degrees expressed to two decimal points for limited precision to protect privacy of landowners.

Found at DOI: http://dx.doi.org/10.3996/072016JFWM-057.S1 (11 KB XLSX),

Table S2. Locations of 28 native Sacramento Valley red fox Vulpes vulpes patwin road kills used to test 
Maxent models, Sacramento Valley, California, 20072009. Location data are provided in Excel format in decimal degrees.

Found at DOI: http://dx.doi.org/10.3996/072016JFWM-057.S12 (10 KB XLSX).

Figure S1. Locations of 42 Sacramento Valley red fox Vulpes vulpes patwin den sites (black circles) and 28 road kills (red circles) in reference to four land-cover types used in Maxent modeling, Sacramento Valley, California, 2007-2009.

Found at DOI: http://dx.doi.org/10.3996/072016JFWM-057.S3 (100 KB PDF).

Figure S2. Locations of 70 Sacramento Valley red fox Vulpes vulpes patwin den sites and road kills (black circles) in reference to geographic landmarks and two Maxent models predicting distribution in the Sacramento Valley, California: (A) the full model, based on vegetation type, distance to grasslands, and distance to development, and (B) a two-variable model, based on vegetation type and distance to grasslands (i.e., excluding distance to development). All data shown were collected during 2007-2009.

Found at DOI: http://dx.doi.org/10.3996/072016JFWM-057.S4 (206 KB PDF).

\section{Acknowledgments}

We thank the many students, volunteers, wildlife professionals, and Sacramento Valley residents who assisted with this research. In particular, we thank $A$. Gonzales, T. Weist, D. Wright, S. Shores, and C. Nguyen for facilitating institutional cooperation, and C. Pells for assistance in website construction. This project was funded principally by the California Department of Fish and Wildlife (agreements nos. P0780029, S0810020), U.C. Davis Center for Population Biology (subcontract no. HBSDF12), and a State Wildlife Grant from the U.S. Fish and Wildlife Service (F12AF00862). Additional funding was provided by the Veterinary Genetics Laboratory and in-kind contributions of the Mammal Ecology and Conservation Unit at the University of California, Davis. We thank two anonymous reviewers and an anonymous associate editor for their comments, which helped to improve this manuscript.

Any use of trade, product, website, or firm names in this publication is for descriptive purposes only and does not imply endorsement by the U.S. Government.

\section{References}

Barbour MT, Keeler-Wolf T, Schoenherr AA. 2007. Terrestrial vegetation of California. 3rd edition. Berkeley: University of California Press.

Brasch A. 2013. Citizen science and its contribution to the conservation of Sacramento Valley red foxes in California. Master's thesis. Wellington, New Zealand: Victoria University of Wellington.
Burnham KP, Anderson DR. 2002. Model selection and multimodel inference. 2nd edition. New York: Springer.

Converse KE. 2012. Genetic mating system and territory inheritance in the Sacramento Valley red fox. Master's thesis. Sacramento: California State University. <http://csus-dspace.calstate.edu/handle/10211.9/ 1977> (December 2016).

Dekker D. 1983. Denning and foraging habits of red foxes, Vulpes vulpes, and their interaction with coyotes, Canis latrans, in central Alberta, 1972-1981. Canadian Field Naturalist 97:303-306.

Elith J, Graham CH, Anderson RP, Dudík M, Ferrier S, Guisan A, RJ Hijmans, Huettmann F, Leathwick JR, Lehmann A, Li J, Lohmann LG, Loiselle BA, Manion G, Moritz C, Nakamura M, Nakazawa Y, Overton JMM, Peterson AT, Phillips SJ, Richardson K, ScachettiPereira R, Schapire RE, Soberón J, Williams S, Wisz MS, Zimmermann NE. 2006. Novel methods improve prediction of species distributions from occurrence data. Ecography 29:129-151.

Elith J, Kearney M, Phillips S. 2010. The art of modelling range-shifting species. Methods in Ecology and Evolution 1:330-342.

Engler R, Guisan A, Rechsteiner L. 2004. An improved approach for predicting the distribution of rare and endangered species from occurrence and pseudoabsence data. Journal of Applied Ecology 41:263-274.

Gibson J. 1975. Riparian habitat along the Sacramento River. Cal-Neva Wildlife Transactions. <http://www. tws-west.org/transactions/Gibson.pdf $>$ (December 2016).

Gosselink TE, Van Deelen TR, Warner RE, Joselyn MG. 2003. Temporal habitat partitioning and spatial use of coyotes and red foxes in east-central Illinois. Journal of Wildlife Management 67:90-103.

Grinnell J, Dixon S, Linsdale JM. 1937. Fur-bearing mammals of California. Berkeley: University of California Press.

Guisan A, Broennimann O, Engler R, Vust M, Yoccoz NG, Lehmann A, Zimmermann NE. 2006. Using nichebased models in improve the sampling of rare species. Conservation Biology 20:501-511.

Guisan A, Zimmermann NE. 2000. Predictive habitat distribution models in ecology. Ecological Modeling 135:147-186.

Johnson CJ, Nielsen SE, Merrill EH, McDonald TL, Boyce MS. 2006. Resource selection functions based on useavailability data: theoretical motivation and evaluation methods. Journal of Wildlife Management 70:347-357.

Jurek RM. 1992. Nonnative red foxes in California. California Department of Fish and Game. Nongame Bird and Mammal Section Report, 92-04. <https://nrm. dfg.ca.gov/FileHandler.ashx?DocumentID=2949 > (December 2016).

Levi T, Wilmers CC. 2012. Wolves-coyotes-foxes: a cascade among carnivores. Ecology 93:921-929. 
Lewis JC, Sallee KL, Golightly RT. 1999. Introduction and range expansion of nonnative red foxes (Vulpes vulpes) in California. American Midland Naturalist 142:372381.

MacKenzie DI, Nichols JD, Royle JA, Pollock KH, Bailey LL, Hines JE. 2006. Occupancy estimation and modeling: inferring patterns and dynamics of species occurrence. New York: Academic Press.

Moore MM. 2009. Impacts of encroaching non-native red foxes on the native Sacramento Valley red fox. Master's thesis. Sacramento, California: California State University.

Nelson C, Lasagna B, Holtgrieve D. 2003. The Central Valley historic mapping project. Chico: California State University Department of Geography and Planning and Geographic Information Center. <http://www. waterboards.ca.gov/waterrights/water_issues/ programs/bay_delta/docs/cmnt081712/sldmwa/ csuchicodptofgeographyandplanningcentralvalley. pdf $>$ (December 2016).

Pearson RG, Raxworthy CJ, Nakamura M, Townsend Peterson M. 2007. Predicting species distributions from small numbers of occurrence records: a test case using cryptic geckos in Madagascar. Journal of Biogeography 34:102-117.

Perrine JD, Pollinger JP, Sacks BN, Barrett RH, Wayne RK. 2007. Genetic evidence for the persistence of the critically endangered Sierra Nevada red fox in California. Conservation Genetics 8:1083-1095.

Peterman WE, Crawford JA, Kuhns AR. 2013. Using species distribution and occupancy modeling to guide survey efforts and assess species status. Journal for Nature Conservation 21:114-121.

Phillips SJ, Anderson RP, Schapire RE. 2006. Maximum entropy modeling of species geographic distributions. Ecological Modeling 190:231-259.

Phillips SJ, Dudík M. 2008. Modeling of species distributions with Maxent: new extensions and a comprehensive evaluation. Ecography 31:161-175.

Phillips SJ, Dudík M, Schapire RE. 2004. A maximum entropy approach to species distribution modeling. Pages 655-662 in Proceedings of the 21st International Conference on Machine Learning. New York: ACM Press.

Roest Al. 1977. Taxonomic status of the red fox in California. Final Report, Job II-1.3. San Luis Obispo: California Polytechnic State University.

Royle JA, Chandler RB, Yackulic C, Nichols JD. 2012. Likelihood analysis of species occurrence probability from presence-only data for modelling species distributions. Methods in Ecology and Evolution 3:545-554.

Sacks BN, Brazeal JL, Lewis JC. 2016. Landscape genetics of the nonnative red fox of California. Ecology and Evolution 14:4775-4791.
Sacks BN, Chomel BB, Kasten RW. 2004. Modeling the distribution and abundance of the nonnative parasite, canine heartworm, in California coyotes. Oikos 105:415-425.

Sacks BN, Moore M, Statham M.J, Wittmer HU. 2011. A restricted hybrid zone between native and introduced red fox (Vulpes vulpes) populations suggests reproductive barriers and competitive exclusion. Molecular Ecology 20:326-341.

Sacks BN, Statham MJ, Perrine JD, Wisely SM, Aubry KA. 2010a. North American montane red foxes: expansion, fragmentation, and the origin of the Sacramento Valley red fox. Conservation Genetics 11:1523-1539.

Sacks BN, Wittmer HU, Statham MJ. 2010b. The native Sacramento Valley red fox. Report to the California Department of Fish and Game, May 30, 2010. <https://www.vgl.ucdavis.edu/cdcg/documents/ 30May2010_FinalReport_ForDistribution_002.pdf $>$ (December 2016).

Sargeant AB, Allen SH. 1989. Observed interactions between coyotes and red foxes. Journal of Mammalogy 70:631-633.

Sargeant AB, Allen SH, Hastings JO. 1987. Spatial relations between sympatric coyotes and red foxes in North Dakota. Journal of Wildlife Management 51:285-293.

Thompson K. 1961. Riparian forests of the Sacramento Valley, California. Annals of the Association of American Geographers 51:294-315.

Tuffly M, Kilgore A. 1998. California Central Valley wetlands and riparian GIS data sets. California Department of Fish and Wildlife. <http://www.dfg. ca.gov/biogeodata/gis/clearinghouse.asp $>$ (December 2016).

Van Etten KW, Wilson KR, Crabtree RL. 2007. Habitat use of red foxes in Yellowstone National Park based on snow tracking and telemetry. Journal of Mammalogy 88:1498-1507.

Warton D, Aarts G. 2013. Advancing our thinking in presence-only and used-available analysis. Journal of Animal Ecology 82:1125-1134.

Wisc MS, Hijmans RJ, Li J, Peterson AT, Graham CH, Guisan A. 2008. Effects of sample size on the performance of species distribution models. Diversity and Distributions 14:763-773.

Yackulic CB, Chandler R, Zipkin EF, Royle JA, Nichols JD, Campbell Grant EH, Veran S. 2012. Presence-only modeling using MAXENT: when can we trust the inferences? Methods in Ecology and Evolution 4:236243.

Zar JH. 1999. Biostatistical analysis. 4th edition. Upper Saddle River, New Jersey: Prentice Hall. 